\title{
Resolution of Challenges That Are Facing Organizations before ITIL Implementation
}

\author{
Mohamed B. Al Mourad and Rozita Johari
}

\begin{abstract}
IT Service Management has become more sophisticated and more critical to the business success. The Information Infrastructure Technology Library (ITIL) is the de facto standard framework for providing guidance to IT service delivery and support processes. Many organizations are either implemented or planning to implement ITIL. Despite many successful case studies many organization were unsuccessful in implementing ITIL due to many reasons. One important factor is that some organizations did not recognize or underestimate the challenges prior to implementation. This exploratory research focuses on the ITIL challenges prior to implementation. IT experts from ten case studies have been interviewed to identify the most reported challenges and the suggestions to resolve these challenges.
\end{abstract}

Index Terms-IT Service management, IT infrastructure library ITIL challenges

\section{INTRODUCTION}

Most organizations today depend on Information Technology (IT) to enable them to achieve the vision and the company's business strategy and objectives. Organisations use IT for different reasons. The success of achieving most business goals of an organisation depends directly on the capability of IT support. IT service emanagement (ITSM) refers to the implementation and management of quality IT services that meet the needs of the business. IT service management is performed by IT service providers through an appropriate mix of people, process and information technology [1]. The cost of IT is never insignificant therfore it is essentil to get good value from IT investments. IT service must be well planned, well designed, well manged and well delivered [2], [3].

To this effect the ITIL introduced a systemetic methodology of managing the organisational IT Services. ITIL is a high-level IT governance framework that explains how to achieve a successful operational service management of IT in an organisation.

The ITIL concept is emerged in early 1972 when IBM started research on quality service delivery called Information Systems Management Architecture (ISMA) and published this in Volume I of the IBM Management series titled "A Management System for the Information Business". During the early 1980 s and responding to growing dependence on IT, the UK Government's Central Computer and Telecommunications Agency (CCTA) developed a set of recommendations. It recognised that without standard

Manuscript received September 14, 2013; revised November 12, 2013 This work was supported by Zayed University Grant No R13076.

The authors are with Zayed University, P. O. Box 19282, Dubai, UAE (e-mail: basel.almourad@zu.ac.ae, rozita.johari@zu.ac.ae). practices, government agencies and private sector contracts had started independently creating their own IT management practices. The recommendations of CCTA resulted in framework that efficiently manages the use of IT resources and this framework was the first version of the current ITIL.

The IT Infrastructure Library originated as a collection of books, each covering a specific practice within IT service management. After the initial publication in 1989-96, the number of books quickly grew within ITIL v1 to more than 30 volumes. In 2000/2001, to make ITIL more accessible (and affordable), ITIL v2 consolidated the publications into 8 logical "sets" that grouped related process-guidelines to match different aspects of IT management, applications, and services.

In July 2011, the 2011 edition of ITIL V3 was published. It provides a more holistic perspective on the full life cycle of services, covering the entire IT organisation and all supporting components needed to deliver services to the customer. Furthermore, ITIL V3 enables organizations to deliver appropriate services and continually ensure they are meeting business goals and delivering benefits. The ITIL V3 best practices are currently detailed within five core publications. introduce five Service Lifecycle stages: Service Strategy, Service Design, Service Transition, Service Operation, and Continual Service Improvement Fig. 1.

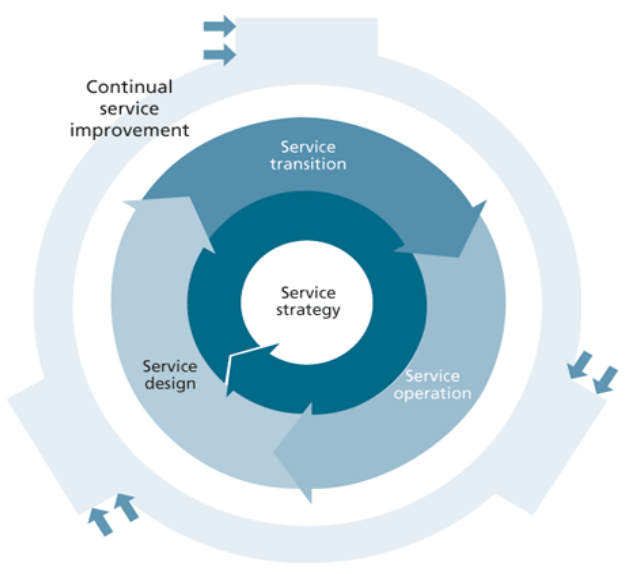

Fig. 1. Service life cycle

Breife descrption of each phases:

Service Strategy Phase: Identify the needs, priorities, demands and relative importance fro desired dervices. It also determines the business value being created through services and the predicted financial resources required to design, deliver and support those services.

Service Design Phase: designs the infrastructure, processes and support mechanisms needed to meet the availability of all elements relevent to the requirements of the customer. It addresses how a planned service solution 
interacts with the larger business and technical environments .

Service Transition Phase: responsible about the delivery of services required by a business into operational use.

Service Operation Phase: Monitor the ongoing availability being provided. Manage and resolve incidents that affect the service operation.

Continual Service Improvement Phase: align and realign IT services to changing business needs. Develop and improve service plans to improve any aspect involved in the management of IT services.

In and across these phases there are twenty six process listed in the Table I. Today, ITIL is the most widely adopted approach for IT. Service Management in the world. It provides a practical, no-nonsense framework for identifying, planning, delivering and supporting IT services to the business.

The remaining of this paper is organised as follows: Section II presents athe motivation and the goal of this research. Section III outlines our research methodology, while Section IV presents and discusses results and finding of or case study. In Section V, we present a summery of the main finding of the paper.

\begin{tabular}{|c|c|}
\hline ITIL Services & Service Processes \\
\hline Service Strategy & $\begin{array}{ll}\text { 1. } & \text { IT service management } \\
\text { 2. } & \text { Service Portfolio Management } \\
\text { 3. } & \text { Financial management for IT services } \\
\text { 4. } & \text { Demand Management } \\
\text { 5. } & \text { Business relationship management } \\
\end{array}$ \\
\hline Service Design & $\begin{array}{ll}\text { 1. } & \text { Design coordination (Introduced in ITIL 2011 Edition) } \\
\text { 2. } & \text { Service Catalogue } \\
\text { 3. } & \text { Service level Management } \\
\text { 4. } & \text { Availability Management } \\
\text { 5. } & \text { Capacity Management } \\
\text { 6. } & \text { Information Security Management System } \\
\text { 7. } & \text { Supplier Management } \\
\end{array}$ \\
\hline Service Transition & $\begin{array}{ll}\text { 1. } & \text { Transition planning and support } \\
\text { 2. } & \text { Change management } \\
\text { 3. } & \text { Service asset and configuration management } \\
\text { 4. } & \text { Release and deployment management } \\
\text { 5. } & \text { Service validation and testing } \\
\text { 6. } & \text { Change evaluation } \\
\text { 7. } & \text { Knowledge management } \\
\end{array}$ \\
\hline Service Operation & $\begin{array}{ll}\text { 1. } & \text { Event management } \\
\text { 2. } & \text { Incident management } \\
\text { 3. } & \text { Request fulfillment } \\
\text { 4. } & \text { Problem management } \\
\text { 5. } & \text { Identity management }\end{array}$ \\
\hline ice Imrovement & \\
\hline
\end{tabular}

TABLE II: Design the CASE Studies BASEd on the Design Model od Dube \& PARE (2001)

\begin{tabular}{|c|c|c|}
\hline Area & Criteria & Description \\
\hline \multirow{6}{*}{$\begin{array}{l}\text { Design } \\
\text { of the } \\
\text { case } \\
\text { study }\end{array}$} & $\begin{array}{l}\text { Research } \\
\text { Purpose }\end{array}$ & Sated in section 2 \\
\hline & $\begin{array}{l}\text { Research } \\
\text { Question }\end{array}$ & Stated in section 2 \\
\hline & $\begin{array}{l}\text { Single versus } \\
\text { multiple-case } \\
\text { design }\end{array}$ & $\begin{array}{l}\text { Multiple cases - } 10 \text { organizations that had either fully implemented, largely implemented or } \\
\text { partially implemented ITIL }\end{array}$ \\
\hline & $\begin{array}{l}\text { Selection of the } \\
\text { cases }\end{array}$ & $\begin{array}{l}\text { The cases (organizations) were selected based on information provided by Information Systems } \\
\text { Audit and Control Association (ISACA) UAE chapter and also based on the recommendation } \\
\text { of the largest consultancy company in MENA }\end{array}$ \\
\hline & $\begin{array}{l}\text { Unites of } \\
\text { analysis }\end{array}$ & Interview of IT Governance/ IT audit/ IT Manager in the selected organizations \\
\hline & $\begin{array}{l}\text { Research } \\
\text { context }\end{array}$ & Cross sectional study conducted over a period of six moths \\
\hline
\end{tabular}

TABLE III: ORGANIZATION CASE STUDIES

\begin{tabular}{|c|c|c|c|c|c|c|c|c|c|c|}
\hline Organizations & $\begin{array}{c}\text { Case } \\
\text { A }\end{array}$ & $\begin{array}{c}\text { Case } \\
\text { B }\end{array}$ & $\begin{array}{c}\text { Case } \\
\text { C }\end{array}$ & $\begin{array}{c}\text { Case } \\
\text { D }\end{array}$ & $\begin{array}{c}\text { Case } \\
\text { E }\end{array}$ & $\begin{array}{c}\text { Case } \\
\text { F }\end{array}$ & $\begin{array}{c}\text { Case } \\
\text { G }\end{array}$ & $\begin{array}{c}\text { Case } \\
\mathrm{H}\end{array}$ & $\begin{array}{c}\text { Case } \\
\text { I }\end{array}$ & $\begin{array}{c}\text { Case } \\
\mathrm{J}\end{array}$ \\
\hline No of Staff & $700+$ & 1000 & 2500 & 500 & 5000 & 3800 & 1100 & 250 & 3000 & 500 \\
\hline No of IT staff & $600+$ & 45 & 100 & 20 & 290 & 87 & 86 & 20 & 80 & 44 \\
\hline Government (G)/Semi-government (S) & $\mathrm{S}$ & $\mathrm{G}$ & G & G & G & G & $\mathrm{S}$ & $\mathrm{S}$ & $\mathrm{S}$ & $\mathrm{S}$ \\
\hline ITIL Version & V3 & V3 & V3 & $\mathrm{V} 2$ & $\mathrm{~V} 2$ & V3 & $\mathrm{V} 2$ & V3 & V3 & V3 \\
\hline Knowledge of ITIL with IT staff/Familiarity & $50 \%$ & $50 \%$ & $35 \%$ & $5 \%$ & $>30 \%$ & $100 \%$ & $90 \%$ & $80 \%$ & $80 \%$ & $70 \%$ \\
\hline Certified ITIL staff & $20 \%$ & $2 \%$ & $5 \%$ & 0 & $<10 \%$ & $25 \%$ & $60 \%$ & $20 \%$ & $20 \%$ & $30 \%$ \\
\hline $\begin{array}{l}\text { Stage of ITIL Implementation } \\
\text { (Fully (F), Largely (L), Partially (P)) }\end{array}$ & $\mathrm{L}$ & $\mathrm{L}$ & $\mathrm{F}$ & $\mathrm{P}$ & $\mathrm{P}$ & $\mathrm{F}$ & $\mathrm{L}$ & $\mathrm{P}$ & $\mathrm{F}$ & $P$ \\
\hline $\begin{array}{l}\text { Reason for ITIL Implementation } \\
\text { Internal/External/Both/Others }\end{array}$ & Internal & Both & Both & Both & $\begin{array}{l}\text { Both } \\
\text { /Other }\end{array}$ & Other & Internal & Internal & Other & Internal \\
\hline
\end{tabular}




\section{Motivation AND THE GOAL OF THIS RESEARCH}

ITIL is being implemented at a rapid pace in organizations worldwide, but despite it's growing use and implementation, organizations are finding it complex [3], difficult to implement [4], and some failed completely [5].

Empirical research in the IT service management domain is in its infancy [6], lacks scientific discussions [7] and has only just emerged [2]. The few studies that have been achieved on ITIL have are mainly focused on implementation issues [8]; ITIL critical success factors [3], [9]; or impact of ITIL implementation on business/IT alignment [10].

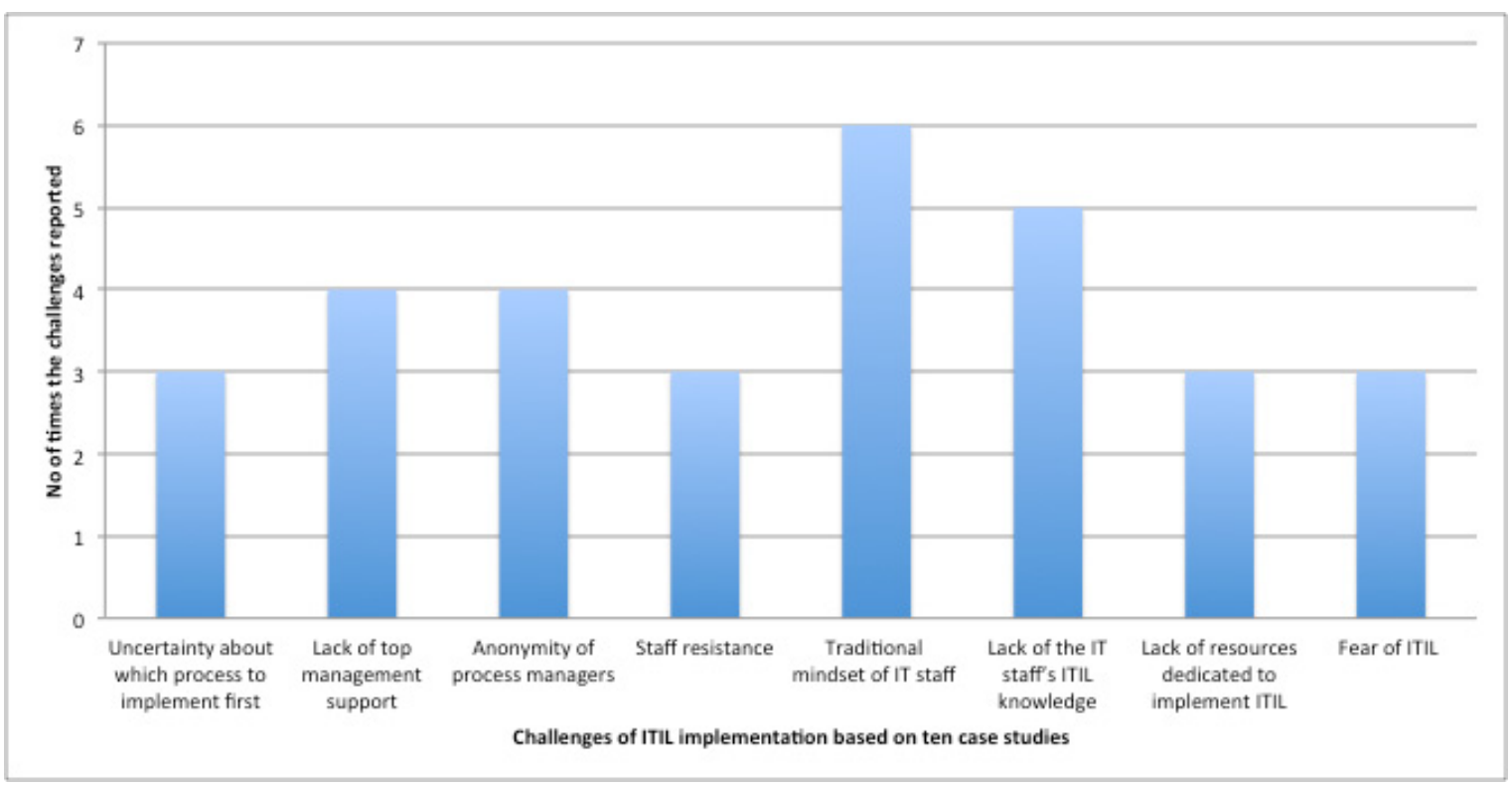

Fig. 2. Frequencies of challenges.

TABLE IV: ITIL CHALLENGES AND THIER RESOLUTIONS

\begin{tabular}{|c|c|c|}
\hline ITIL Challenges before implementation & Cases & Resolution of challenges \\
\hline Uncertainty about which process to implement first & $\mathrm{D}, \mathrm{G}, \mathrm{H}$ & $\begin{array}{l}\text { Always recommended to start with Incident Management (IM), } \\
\text { followed by Problem Management, Configuration Management and } \\
\text { Change Management }\end{array}$ \\
\hline Lack of top management support & $\mathrm{A}, \mathrm{C}, \mathrm{D}, \mathrm{H}$ & $\begin{array}{l}\text { Securing executive support must be done at a very early stage and the } \\
\text { initiative of ITIL adoption must be embedded in the organization } \\
\text { strategy to assure management support before progressing to the } \\
\text { implementation }\end{array}$ \\
\hline Anonymity of process managers & $\mathrm{C}, \mathrm{D}, \mathrm{I}, \mathrm{J}$ & $\begin{array}{l}\text { Defining single point of contact for every process at early stage of } \\
\text { ITIL implementation is highly important }\end{array}$ \\
\hline Staff resistance & A, E, I & $\begin{array}{l}\text { Running awareness sessions is important to guarantee buy-in of the } \\
\text { staff at different levels. Stakeholders must understand the benefit of } \\
\text { ITIL adoption. }\end{array}$ \\
\hline Traditional mindset of IT staff & $\begin{array}{l}\text { A, C, D, E, } \\
\text { I, J }\end{array}$ & $\begin{array}{l}\text { The mindset of IT staff should significantly balance the focus on } \\
\text { customer and technology itself. }\end{array}$ \\
\hline Lack of the IT staff's ITIL knowledge & $\begin{array}{l}\mathrm{B}, \mathrm{C}, \mathrm{E}, \mathrm{F}, \\
\mathrm{G}\end{array}$ & $\begin{array}{l}\text { All IT staff must be ITIL educated at least to the Foundation level } \\
\text { External consultant can by hired to overcome the limitation of IT } \\
\text { staff knowledge }\end{array}$ \\
\hline Lack of resources dedicated to implement ITIL & $\mathrm{B}, \mathrm{F}, \mathrm{G}$ & $\begin{array}{l}\text { Sufficient resources (manpower; technology; budget, etc.) must be } \\
\text { acquired and allocated to the ITIL manager personnel }\end{array}$ \\
\hline Fear of ITIL & $\mathrm{A}, \mathrm{B}, \mathrm{C}$ & $\begin{array}{l}\text { ITIL training and certification are highly recommended prior to ITIL } \\
\text { implementation }\end{array}$ \\
\hline
\end{tabular}

ITIL adoption is a very complex activity as it calls for the thorough reengineering of ITSM processes, involving many staff and systems. If it is not appropriately planned and budgeted then it will fail through lack of resources and will be very difficult to revive [10].

While most of the research in this area focuses on ITIL implementation and best practices, this research argues that in order for IT to achieve business support a proper planning of ITIL implementation that should be carefully considered. A good identification and understanding of ITIL challenges prior to implementation of ITIL can reduce the occurrence of IT failures, improve service levels and customer satisfaction, and reduce both fixed and variable costs as it allows IT service to gain credibility, improve performance, reduce cost and maximize efficiency in the company by a more productive use of information system [11]. The objectives of this paper is to focus on the challenges that are facing organization prior to ITIL implementation and try to suggest resolutions to overcomes these diverse challenges.

\section{RESEARCH METHODOLOGY}

As the study is exploratory in nature, the study follows the qualitative approach through the case study method of data collection. The case study method provides the opportunity to ask penetrating questions and to capture the 
richness of organizational behavior. The design of the case study is given in Table II. is based on the criteria used to assess IS case studies by [12].

In view of the requirement for "information rich" cases, 10 organizations based in Dubai were carefully selected [13]. Cases from Dubai (one of the seven emirates/states of United Arab Emirates) are chosen because Dubai is a role model in IT governance implementation. It instituted the Financial Audit Department (FAD) through a decree in 1995 and IS audit has been made mandatory since 2001 which coversgovernment departments, public corporations, companies with more than $25 \%$ government shareholding, organizations supported by a government financial subsidy, and/or any other body where an audit is commissioned by the Ruler of Dubai, and the FAD has done more than 40 IT Governance assessments. Two organizations had "successfully" and fully implemented ITIL, three had largely implemented ITIL and five have partially implemented ITIL. Due to commercial sensitivity of the information and comments, the actual names of the organizations can't be disclosed. The ten cases are referred to throughout the case discussion as case A- J. Table II. Introduces each organization in terms of size, nature, and ITIL version, knowledge of ITIL within the staff, stage of ITIL implementation and reason of ITIL implementation. ITIL experts in these organizations were interviewed and questioned.

The questionnaire contains three main parts: Part A, contains questions about the organization (i.e. size, nature, number of IT staff, etc.). Part B, contains questions about the challenges that faces organization before implementing ITIL. Part C, gathers feedback about the best practice for preparing for ITIL implementation and overcome any potential challenges.

\section{FINDING}

The interview's questionnaire outcome of the ten case studies were analyzed to identify patterns and summarize the main characteristics of approach and to select quotations that are supportive of the patterns and themes identified across all cases [14]. The cross case analysis of the 10 organizations has generated eight important challenges that must be considered and resolved before implementing ITIL. The challenges are detailed and illustrated with quotation from the ITIL personnel interviewed and questioned. Table V. summarizes the challenges and their resolution that are emerged in each of the 10 organizations. Fig. 2 presents the frequency of each challenge. The traditional mindset of IT staff scores the first challenge. The lack of the IT staff's ITIL challenges score second. The suspicious of which process to start and the lack of top management support score the thirds and the rest four challenges score the same.

\section{A. Uncertainty about Which Process to Implement First}

All stakeholders need to understand that implementing ITIL is a significant transformational change program. "It is a move from IT service management to service management, from knowledge centric to process centric and from functional organization to process organization" (cases D, G and $\mathrm{H}$ ). Before ITIL implementation, the involved manager needed to benchmark the activities of the IT infrastructure to determine how well it is performing and decide the extent the organization want to implement ITIL's best practices. IT goals must be aligned to the key business and enterprise goals. The gap between how the organization is performing and the ITIL best practice target [9] must be identified in order to decide which processes must be implemented or improved first. As stated in Table I ITIL comprises of ten services and twenty sixes processes. Many organizations are either not sure which service to implement first or/and attempt to implement too many services at once, causing inaccuracy, staff confusion and poor coordination between services and their processes counterparts. If the organization Incident Management (IM) Process hasn't reached a stable state it, is always recommended to start with. The goal of IM is to restore normal operation as quickly as possible to clients thus; IM is a foundation process on which many other processes will depend. Problem Management, Configuration Management and Change Management are the next processes to consider.

\section{B. Lack of Top Management Support}

Strong continuous executive management support is the one of the top requirements for successful ITIL implementation. "Securing executive support must be done at a very early stage and the initiative of ITIL adoption must be embedded in the organization strategy to assure management support before progressing to the implementation" (cases A, C, D and H). Most executives have the same problems. "They want faster service, higher quality service and cheap service". Executives need to understand that implementing and recognizing ITIL benefits needs time. Securing executive support is necessary for three reasons: First, to avoid hesitation and reluctances that might appear at different levels and across various manpower. Second, to secure capital for resources such as hardware, software, training and consultancy. Third, to authorize policies and impose these policies across the whole organization.

\section{Anonymity of Process Managers}

"Defining single point of contact for every process at early stage of ITIL implementation is highly important" (cases C, D, I and J). When people recognize they don't have the power to change things, they become disengaged and more liability and burden are laid on team leader, adding extra anxiety on them. The management and the team must work in harmony and they need to identify the process owners and work to set common commitment.

\section{Staff Resistance}

Staff resistance at different levels is experienced in the responses of this research (cases $\mathrm{A}, \mathrm{E}$ and I) and also in other researches [15]. Surprisingly, initial resistance comes from technical IT staff.

For example, the help desk staff was unenthusiastic to log incidents and consequently document the actions taken. Doing so, they felt it was a waste of time and hinder them from doing their work efficiently and rapidly. Running awareness sessions is important to guarantee buy-in of the staff at different levels. Stakeholders must understand the benefit of ITIL adoption. A case study can be presented 
and/or ITIL publications can be used to explain the benefit of ITIL. It is highly important to update the IT (Potg2005).

\section{E. Traditional Mindset of IT Staff}

"The mindset of IT service providers is normally technology focused rather than customer centric" (cases A, C, D, E, I and J). This mindset should significantly balance the focus on customer and technology itself. This can be done by running educational sessions and raising the ITIL friendly culture.

\section{F. Lack of the IT Staff's ITIL Knowledge}

Lack of ITIL knowledge is big obstacle. "All IT staff must be ITIL educated at least to the Foundation level" (cases B, C, E, F and G). External consultant can by hired to overcome the limitation of IT staff knowledge. If organizations decided to depends greatly on external consultant a special attention must be taken to ensure that the knowledge emerged before and after ITIL implementation is clearly documented and transferred to the organization's staff.

\section{G. Lack of Resources Dedicated to Implement ITIL}

Before implementing ITIL sufficient resources (manpower; technology; budget, etc.) must be acquired and allocated to the ITIL manager personnel (cases B, F and G). To overcome a shortage of resources in this challenge, the advice is to keep the implementation scope to the minimum and begin with the processes that are already established (e.g. incident management). To gain more acceptance to change when improvements are tangible to all stakeholders including those who are responsible about allocation required resources.

\section{H. Lack of Resources Dedicated to Implement ITIL}

Before implementing ITIL sufficient resources (manpower; technology; budget, etc.) must be acquired and allocated to the ITIL manager personnel (cases B, F and G). To overcome a shortage of resources in this challenge, the advice is to keep the implementation scope to the minimum and begin with the processes that are already established (e.g. incident management). To gain more acceptance to change when improvements are tangible to all stakeholders including those who are responsible about allocation required resources.

\section{Fear of ITIL}

The early version of ITIL (i.e. version 1) has more than 30 volumes. ITIL v2 consolidated the publications into nine logical "sets" that grouped related process-guidelines to match different aspects of IT management, applications, and services. Even though ITIL v3 has cut down the publication into five volumes many IT manager are still scared to implement ITIL (cases C and E). The fear of ITIL still exists as there is lack of process model describing how to implement ITIL step by step. To over come the fear many IT manager call for more ITIL practical books and more publications to describe some ambiguity of ITIL implementation (i.e. where, how and when to start). Further more, ITIL training and certification are highly recommended prior to ITIL implementation

\section{CONCLUSION}

Organizations that choose to implement ITIL to improve their performance and gain competitiveness should carefully consider all challenges that many organizations have faced and consider action to resolve those challenges ahead of ITIL implementation. Challenges that are human reflected can be resolved by education, awareness and training. Challenges that are related to money can be resolved by identifying organization priorities and allocate the required budget. Finally, IT goals must be aligned to the key business and enterprise goals processes must be implemented or improved first. In future we are planning to extend our work to focus on the best practice that organizations need to consider when they develop the service strategy phase of ITIL implementation

\section{ACKNOWLEDGMENT}

The authors wish to dedicate there thanks to the IT service manager for their participation in this research. A grant number R13076 from Zayed University in UAE supported this work.

\section{REFERENCES}

[1] ITIL Officialsite.com. (2012). ITIL Glossaries. [Online]. Available: http: www.itilofficialsite.com/InternationalActivities/ITILGlossaries_2.aspx

[2] J. Iden and L. Langeland, "Setting the stage for a successful ITIL adoption: a delphi study of IT experts in the norwegian armed forces," Information Systems Management, vol. 27, no. 2, pp. 103-112, 2010.

[3] C. Pollard and A. C. Steel, "Justifications, strategies, and critical success factors in successful ITIL implementations in US and Australian companies: An exploratory study," Information Systems Management, vol. 26, pp. 164-175, 2009.

[4] S. Shang and S. F. Lin, "Barriers to Implementing ITIL-a multi-case study on the service-based industry," Contemporary Management Research, vol. 6, no. 1, pp. 53-70, 2010.

[5] R. Pereira and M. Silva, "A Maturity Model for Implementing ITIL," in Proc. IEEE 6th World Congress on Services, vol. 3, 2010.

[6] S. Conger, M. Winniford, and L. E. Harris, "Service management in operations," American Conference on Information Systems (AMCIS), 2008.

[7] A. Hochstein, G. Tamm, and W. Brenner, "Service oriented IT management: benefit, cost and success factors," The European Conference on Information Systems (ECIS), pp. 26-28, 2005.

[8] A C. Steel and W. G. Tan, "Implementation of IT infrastructure library (ITIL)," in Proc. IT Governance International Conference, pp. $1-13,2005$.

[9] M. Nicho and M. B. Almourad, "Success factors for integrated ITIL deployment: an IT governance classification," Journal of Information Technology Case and Application Research (JITCAR), vol. 14, no. 1, 2003 ,

[10] S. Haes and W. Grembergen, "IT governance structures, processes and relational mechanisms: achieving IT/business alignment in a major belgian financial group," in Proc. the 38th International Conference on Systems Sciences, Hawaii, pp. 275-285, 2005.

[11] S. Sebaaoui and M. Lamrini, "Implementation of ITIL in a moroccan company: the case of incident management process," International Journal of Computer Science Issues, vol. 9, no. 4, 2012.

[12] L. Dubé and G. Paré, "Case Research in information systems: current practices, trends, and recommendations," Montréal: École des Hautes Études Commerciales de Montréal. Cahier du GReSI, vol. 1, no. 12, 2012.

[13] M. Patton, Qualitative Research and Evaluation Methods (Third ed.). London: Sage, 2002.

[14] J. W. Creswell, Qualitative inquiry and research design: Choosing among five designs. CA: Sage, 1998.

[15] B. C. Potgieter and C. Lew, "Evidence that use of the ITIL framework is effective," in Proc. 18th Annual Conference of the National Advisory Committee on Computing Qualifications, Tauranga, 2005. 


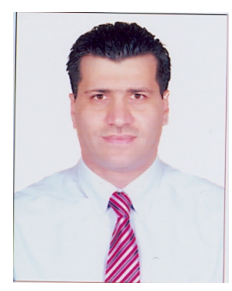

M. B. Almourad has received his BSc in informatics engineering from Aleppo University, Syria, and his PhD degree in Computer Science from Cardiff University of Wales, United Kingdom. He has served in various International Universities. He is currently an Assistant Professor in Zayed University, Dubai, UAE. Dr. Al-Mourad is active in several research areas where he published numerous articles including:IT Service Management, Heterogeneous Data Management, Semantic Web, Web Accessibility and Community of Practice.
Rozita Johari obtained her BSc in computer science and mathematics from Pittsburg State University, USA, MSc in Computer Science from Illinois Institute of Technology, USA and PhD in Computer Science specialized in Parallel Systems from University Putra Malaysia, Malaysia. She held faculty position in several universities in Malaysia and UAE. She is currently an Assistant Professor in Zayed University in Dubai.

Her research interests include Parallel and Distributed Computing, Scientific Computing, High Speed Networks, Mobile Computing and Technology for Education and Learning. 